\title{
The tale of two climates- Baltimore and Phoenix urban LTER sites
}

\author{
Anthony Brazel ${ }^{1, *}$, Nancy Selover ${ }^{1}$, Russell Vose $^{1}$, G ordon Heisler ${ }^{2}$ \\ ${ }^{1}$ Department of G eography and Office of Climatology, A rizona State University, Tempe, A rizona 85287-0104, USA \\ ${ }^{2}$ US Department of A griculture Forest Service, N ortheastern Research Station, 5 M oon Library, SUNY-ESF, \\ Syracuse, N ew York 13210, USA
}

\begin{abstract}
Two Long-Term Ecological Research (LTER) sites now include urban areas (Baltimore, Maryland and Phoenix, Arizona). A goal of LTER in these cities is to blend physical and social science investigations to better understand urban ecological change. Research monitoring programs are underway to investigate the effects of urbanization on ecosystems. Climate changes in these urban areas reflect the expanding population and associated land surface modifications. Long-term urban climate effects are detectable from an analysis of the GHCN (Global Historical Climate N etwork) database and a comparison of urban versus rural temperature changes with decadal population data. The relation of the urban versus rural minimum temperatures $\left(\Delta T \min _{\mathrm{u}-\mathrm{r}}\right)$ to population changes is pronounced and non-linear over time for both cities. The $\Delta \operatorname{Tmax}_{\mathrm{u}-\mathrm{r}}$ data show no well-defined temporal trends.
\end{abstract}

KEY WORDS: Long-Term Ecological Research - Urban climate - GHCN temperature time series . Baltimore $\cdot$ Phoenix $\cdot$ Land use $\cdot$ Land cover

\section{INTRODUCTION}

Two urban Long-Term Ecological Research (LTER) sites have been established in the national network of LTER locations-Baltimore, Maryland (Fig. 1) and Phoenix, Arizona (Fig. 2) (Web sites: http://baltimore. umbc.edu/lter/ and http://caplter.asu.edu/). All LTER sites are supported by the National Science Foundation, often in cooperation with other agencies (e.g., USDA Forest Service and US Geological Survey in Baltimore), by funding arrangements that are designed to facilitate investigations into ecological issues and problems that are better studied over long periods of time (Greenland \& Swift 1991). Scientists in the LTER programs realize that there is a fundamental need to examine climate variability at these sites to understand the forcing role of climate on ecosystems, and the feedbacks of ecosystem components on local and regional climate (desertification, urbanization, deforestation,

*E-mail: abrazel@asu.edu etc.). The LTER national climate committee recognizes that it is imperative to investigate various time and space scales of climate variability in terms of potential influences on ecosystem responses that may be taking place both synchronously across an array of sites and separately at each site.

For LTER sites, investigators of climate variability should address trends in the overall climate system as well as unique climate events through time. Unlike other LTER sites, the major focus for urban sites must be explicit analyses of local-scale (i.e., ca $100 \mathrm{~m}$ to $50 \mathrm{~km}$ horizontally) changes traceable to the variable temporal and spatial dimensions of urbanization and growth. Research on the biological and ecological environment at the 2 urban LTER sites is being designed and is ongoing, much like at the other sites in the network (see Web sites, listed above). Little specific research on the climate environment, especially the study of urban climate, within these 2 sites has yet been conducted through the auspices of the LTER program. This paper is a contribution in this regard. However, there has been considerable past climatic and 

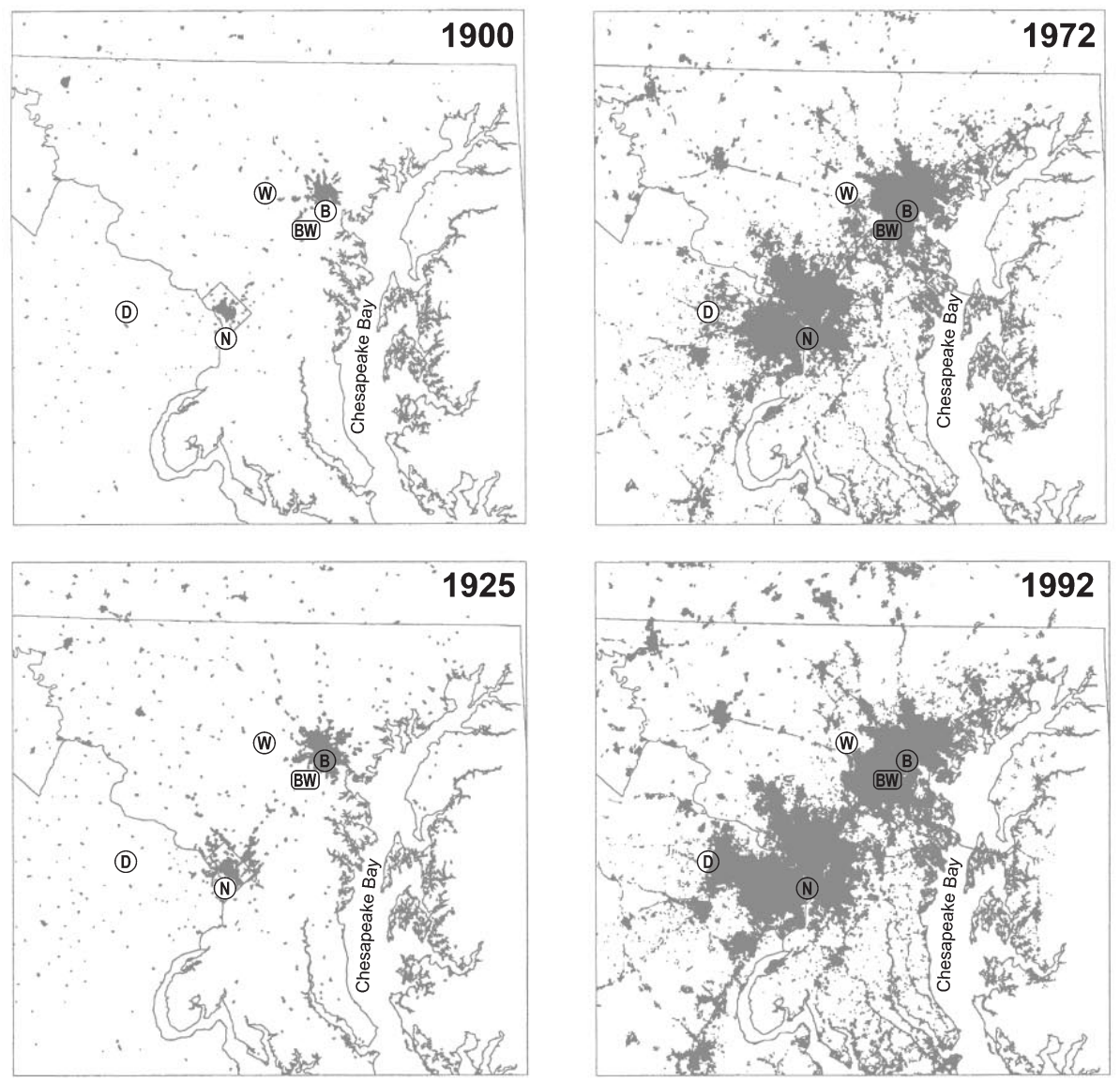

\section{Stations}

(11) Woodstock

(B) Baltimore WSO

BW Baltimore Washington AP

(D) Washington Dulles AP

(N) Washington National AP

Land Use

Grey pattern indicates built-up areas.

\begin{tabular}{|c|c|c|}
\hline 20 & 40 & 60 Miles \\
\hline
\end{tabular}

Fig. 1. Land use changes for the Washington/Baltimore region showing the spread of the built-up areas from 1900 through 1992. See Foresman et al. (1997) regarding the development of the data shown here. Data are available at http://www. research.umbc.edu/bwrdc/bwrc/ Products/datacat/hiltdata/hiltdata. htm through the Baltimore Washington Regional collaboratory

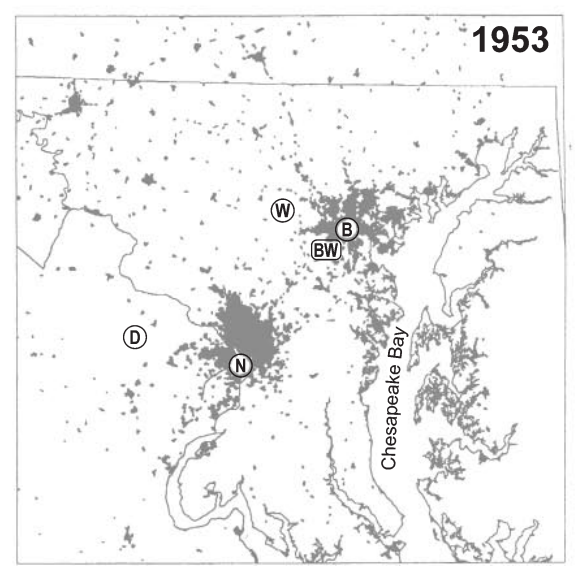

meteorologic research performed in and near the 2 cities of Baltimore and Phoenix. Previous researchers have studied Baltimore and Phoenix by analyzing the differences between rural and urban sites, and the relation between land cover and climate characteristics of the active city surface layer through remote sensing and modeling efforts (e.g., Mitchell 1953, 1961, Pease et al. 1976, 1980, Landsberg 1981, and Gallo \& Owen 1998 for Baltimore and surroundings;
Brazel et al. 1993 and Balling \& Brazel 1987 for the Phoenix area, some of which is also reviewed in Pon et al. 1998).

Our purpose in this paper is to present a comparative view of temporal temperature patterns for the 2 cities and to indicate the nature of past research on climate for the 2 locations. Our hope is to foster specific integrative research for each site and between the 2 sites to assist researchers in learning more about the climate-ecosystem variations that are evident and traceable to urban effects in humid versus arid cities in general.

\section{HISTORICAL CLIMATE DATA ANALYSIS OF THE URBAN EFFECT}

Baltimore and Phoenix differ considerably in their climatic regimes-one is representative of a humid, mid-latitude, east-coast climate, the other of an arid, subtropical latitude environment. Atmospheric circulation and synoptic controls, seasonal, diurnal, and annual temperatures, moisture, air flow, and exposure 

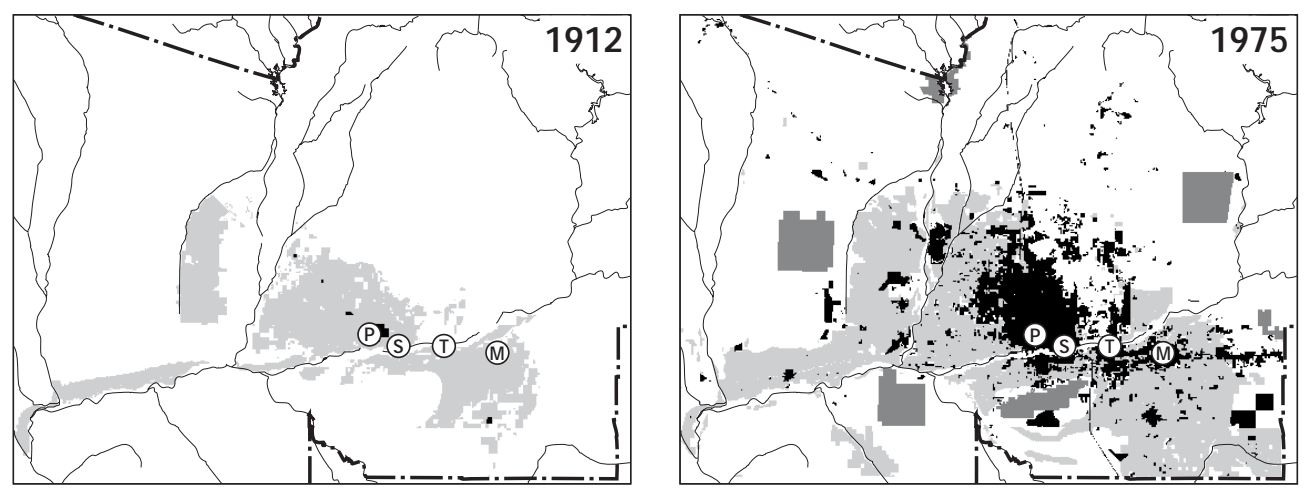
Stations
(P) Phoenix
(5) Phoenix Sky Harbor AP
(T) Tempe
(M) Mesa
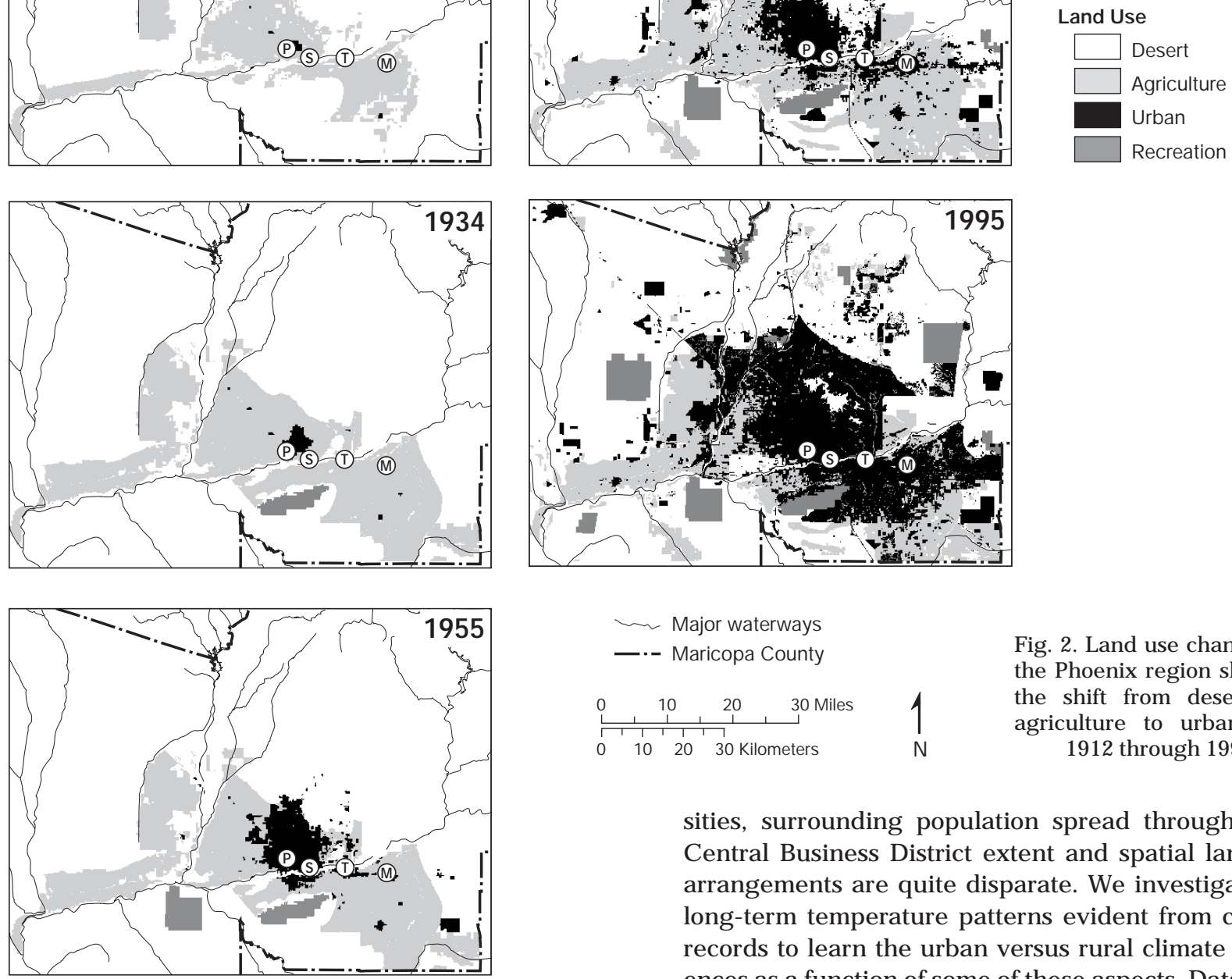

Fig. 2. Land use changes for the Phoenix region showing the shift from desert and agriculture to urban from 1912 through 1995

sities, surrounding population spread through time, Central Business District extent and spatial land use arrangements are quite disparate. We investigate the long-term temperature patterns evident from climate records to learn the urban versus rural climate differences as a function of some of these aspects. Data were accessed from NOAA's archives of the Global Historical Climate Network (GHCN Web site: http://www.ncdc.

to marine influences fundamentally differ between the 2 sites (Court 1974). These factors contribute to differences in the magnitude of urban effects between the 2 cities. As further comparisons between these 2 LTER urban sites are made, an appreciation for the climatic regime differences and their respective synoptic climatologies will be of considerable fundamental importance. However, in this paper, we strive to illustrate some common themes of the urban effect on local climate in relation to population changes and surface variations.

Although today's greater Washington/Baltimore and Phoenix metropolitan areas are somewhat similar in overall population (over 2 million for each), the timing of their development, growth rates, population dennoaa.gov/cgi-bin/ghcn/temp) for Baltimore Weather Service Office, Washington Reagan National AP (airport), Washington Dulles AP, and Woodstock, and, in the Arizona case, for M esa, Phoenix Sky Harbor AP, and Sacaton. We further supplemented the GHCN data with some other sites (downtown Phoenix and Tempe).

The GHCN data have been extensively data-quality controlled (Peterson \& Vose 1997, Peterson et al. 1998) and contain stations with long-term monthly average maximum and minimum temperatures and total monthly precipitation data from rural and urban locales in the 2 regions. We restrict our analysis in this paper to temperature.

Landsberg (1981) compared 2 sites to illustrate the urban effect for Baltimore-Woodstock (W), a small 
rural seminary site to the west, and Baltimore WSO (B) in the downtown area at the head of the Inner Harbor in the city (Fig. 1). We present data in relation to Woodstock for 3 other stations - Baltimore-Washington International AP (BW), Washington Dulles AP (D), and Washington National AP (N) for the month of July. $M$ itchell (1961) suggests that this month is a time when urban effects appear to be most accentuated due to the lack of larger synoptic-scale influences.

For the Phoenix area (Fig. 2), 5 sites were analyzed for the month of May-a time of mostly clear, calm conditions (the monsoon in late J une and J uly dampens urban effects). They are: (1) Phoenix Sky Harbor AP (S) - a short-duration first-order National Weather Service site in the center of the Salt River Valley's metro area; (2) M esa (M); (3) Tempe (T); (4) downtown Phoenix (P); and (5) Sacaton - a small rural town (current population less than 1500) on the Gila Indian Reservation not shown on Fig. 2, but ca $25 \mathrm{~km}$ southeast from the greater Phoenix metro area. All but downtown Phoenix and Tempe are in the archives of the GHCN. In the case of Tempe's time series, 4 stations existed spanning the overlapping periods 1905-1952, 1926-1984, and 1953-1982. Since 1982, the station has been located on the campus of Arizona State University. After careful examination, we reduced these 4 series into 1 series from 1905 to 1984 by adjusting all site temperatures to the 1926-1984 site (in a neighborhood closest to the urban center). This was accomplished by analyzing overlapping periods and developing regression equations to adjust data to the 1926-1984 site. Thus, less reliability should be placed on results for that station. Sites are listed in Table 1 and details of the downtown Phoenix and Tempe sites are shown. All other site metadata are found in GHCN archives and are not repeated here.

Instrumentation, sensor height, and location of sensors can induce variations in temperature trends and present problems for researchers looking at temporal and spatial characteristics of rural and urban stations.

Table 1. (a) Sites used in the study and (b) details of non-GHCN (Global Historical Climate Network) sites used. CRS: Cotton Region Shelter; LST: Iocal standard time; PO: Post Office

\begin{tabular}{|c|c|c|c|c|c|c|c|}
\hline \multicolumn{8}{|c|}{ (a) Sites used in the study } \\
\hline \multicolumn{3}{|c|}{ Name } & Latitude & Longitude & Elevation (m) & Record length used & $\mathrm{GHCN}$ \\
\hline \multicolumn{3}{|c|}{ Baltimore WSO } & $39^{\circ} 28^{\prime}$ & $76^{\circ} 37^{\prime}$ & 4.3 & 1900-1994 & Yes \\
\hline \multicolumn{3}{|c|}{ Baltimore-Washington Internatinal AP } & $39^{\circ} 11^{\prime}$ & $76^{\circ} 40^{\prime}$ & 45.1 & 1951-1997 & Yes \\
\hline \multicolumn{3}{|c|}{ Washington Dulles AP } & $38^{\circ} 56^{\prime}$ & $77^{\circ} 27^{\prime}$ & 93.3 & 1963-1995 & Yes \\
\hline \multicolumn{3}{|c|}{ Washington National AP } & $38^{\circ} 51^{\prime}$ & $77^{\circ} 02^{\prime}$ & 18.0 & $1945-1995$ & Yes \\
\hline \multicolumn{3}{|c|}{ Woodstock } & $39^{\circ} 33^{\prime}$ & $76^{\circ} 52^{\prime}$ & 140.2 & $1900-1995$ & Yes \\
\hline \multicolumn{3}{|l|}{ Mesa } & $33^{\circ} 25^{\prime}$ & $111^{\circ} 49^{\prime}$ & 376.5 & 1905-1988 & Yes \\
\hline \multicolumn{3}{|l|}{ Phoenix City } & $33^{\circ} 57^{\prime}$ & $112^{\circ} 05^{\prime}$ & 330.8 & 1905-1995 & No \\
\hline \multicolumn{3}{|l|}{ Sacaton } & $33^{\circ} 04^{\prime}$ & $111^{\circ} 45^{\prime}$ & 391.8 & $1908-1995$ & Yes \\
\hline \multicolumn{3}{|l|}{ Sky Harbor } & $3^{\circ} 26^{\prime}$ & $112^{\circ} 01^{\prime}$ & 336.0 & 1948-1995 & Yes \\
\hline Tempe 35 & & & $3^{\circ} 23^{\prime}$ & $111^{\circ} 56^{\prime}$ & 359.7 & 1908-1952 & No \\
\hline Tempe & & & $3^{\circ} 26^{\prime}$ & $111^{\circ} 56^{\prime}$ & 350.6 & $1926-1984$ & No \\
\hline Tempe UA Citrus & & & $3^{\circ} 25^{\prime}$ & $111^{\circ} 58^{\prime}$ & 359.7 & $1953-1982$ & No \\
\hline Tempe ASU & & & $3^{\circ} 25^{\prime}$ & $111^{\circ} 56^{\prime}$ & 356.7 & $1982-1995$ & No \\
\hline (b) Details of chang & for the non & $\mathrm{HCN}$ sites & sed in & paper & & & \\
\hline Station & Latitude & Longitude & Eleva & $n(m)$ & Years time & Instrument & Observation \\
\hline Phoenix PO & $33^{\circ} 27^{\prime}$ & $112^{\circ} 04^{\prime}$ & & & 1876-1901 & CRS - Max-Min & 17:00 h LST \\
\hline Phoenix PO & $33^{\circ} 27^{\prime}$ & $112^{\circ} 05^{\prime}$ & & & $1901-1924$ & CRS - Max-M in & 17:00 h LST \\
\hline Phoenix PO & $33^{\circ} 27^{\prime}$ & $112^{\circ} 05$ & & & $1924-1936$ & CRS - Max-M in & 17:00 h LST \\
\hline Phoenix PO & $33^{\circ} 27^{\prime}$ & $112^{\circ} 04^{\prime}$ & & & $1936-1954$ & CRS - Max-M in & $17: 00$ h LST \\
\hline Phoenix PO & $33^{\circ} 27^{\prime}$ & $112^{\circ} 04^{\prime}$ & & & $1954-1958$ & CRS - Max-Min & 17:00 h LST \\
\hline Phoenix PO & $33^{\circ} 27^{\prime}$ & $112^{\circ} 04^{\prime}$ & & & $1958-1968$ & CRS - Max-M in & 17:00 h LST \\
\hline Phoenix PO & $33^{\circ} 27^{\prime}$ & $112^{\circ} 04^{\prime}$ & & & $1968-1982$ & CRS - Max-M in & 17:00 h LST \\
\hline Phoenix PO & $33^{\circ} 27^{\prime}$ & $112^{\circ} 04^{\prime}$ & & & $1982-1987$ & CRS-M ax-M in & 17:00 h LST \\
\hline Phoenix PO & $33^{\circ} 27^{\prime}$ & $112^{\circ} 04^{\prime}$ & & & 1987-1999 & MMTS & 17:00 h LST \\
\hline Tempe $3 S^{a}$ & $33^{\circ} 23^{\prime}$ & $111^{\circ} 56^{\prime}$ & & & 1908-1952 & CRS - M ax-Min & 08:00 h LST \\
\hline Tempe $^{a}$ & $33^{\circ} 26^{\prime}$ & $111^{\circ} 56^{\prime}$ & & & $1926-1984$ & CRS - Max-M in & 08:00 h LST \\
\hline & & & & & $1982-1984$ & CRS - Max-M in & 17:00 h LST \\
\hline Tempe UA Citrus ${ }^{a}$ & $33^{\circ} 25^{\prime}$ & $111^{\circ} 58^{\prime}$ & & & 1953-1982 & CRS - Max-M in & 08:00 h LST \\
\hline Tempe ASU a & $33^{\circ} 25^{\prime}$ & $111^{\circ} 56^{\prime}$ & & & $1982-1990$ & CRS-M ax-M in & 17:00 h LST \\
\hline
\end{tabular}


We inspected station histories to see if there were any obvious changes that might be coincident with breaks in the progression of temperatures through time. In the Phoenix area, the most obvious effect that has been carefully observed is a station move from the airport's parking lot premises to off the runway system in 1994 (discussed in Section 4). In the case of the Baltimore sites, there remains suspicion about some aspects, particularly of the maximum temperature observations at a number of sites for recent years (R. Leffler 1999 pers. comm.).

\section{THE RURAL SITES CHOSEN}

Both Woodstock and Sacaton are at least 20 to $25 \mathrm{~km}$ outside of built-up urban areas. The Woodstock site has incomplete records in the late 1800 s and early 1900s, prior to 1912. Graphs of the maximum and minimum temperature time series of the rural sites, Sacaton and Woodstock, are shown in Fig. 3. There are no apparent long-term trends in the data for maximum and minimum temperatures, with the exception of the earlier period for Woodstock, and the very recent increase in minimum temperatures at Woodstock and Sacaton. Thus, the rural sites chosen display a relatively stable background series against which the urban sites can be compared.

\section{BALTIMORE AND PHOENIX URBAN-RURAL RESULTS}

Fig. 4 shows the differences between the chosen rural sites in each urban LTER and the respective airport and city stations for maximum ( $\left.\Delta \mathrm{Tmax}_{\mathrm{u}-\mathrm{r}}\right)$ and minimum ( $\left.\Delta T \min _{u-r}\right)$ monthly temperatures (using J uly for Baltimore and May for Phoenix). The resulting urbanrural temperatures were fitted by a LOWESS smoothing procedure - a process that smooths the time series of temperature differences similar to a running mean of about $15 \mathrm{yr}$, thus removing most of the effect of short-term chance anomalies (Wilkinson 1997). This is important especially since there appears to be some suspicion of sensor and location moves, particularly for the recent records for each area's airport and downtown sites.

For the Baltimore area, note the trend of gradually rising differences of the minimum temperatures for Baltimore WSO-Woodstock peaking in the mid-1970s at an average of nearly 4 to $5^{\circ} \mathrm{C}$. The differences in the maximum temperatures have attained a peak difference in recent decades near $1.7^{\circ} \mathrm{C}$. However, the maximum temperatures have been suspected to be overestimated for this site (R. Leffler 1999 pers. comm.).

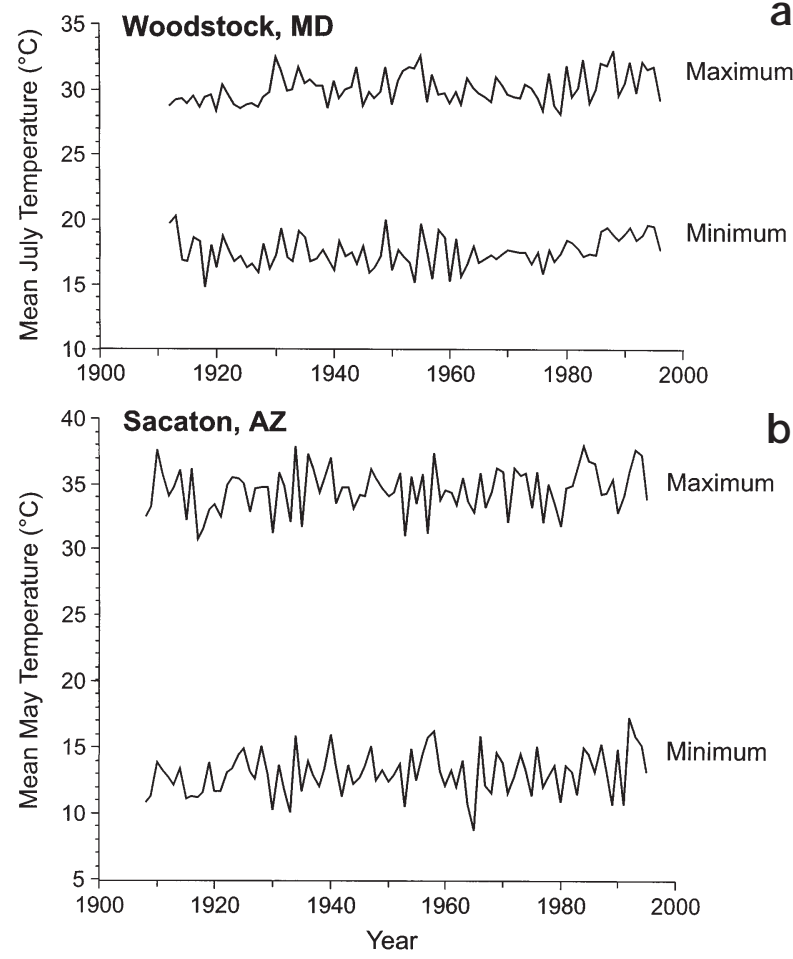

Fig. 3. Time series of maximum and minimum temperatures for the 2 rural sites: (a) Woodstock, MD, and (b) Sacaton, AZ

Our J uly analysis is consistent with Landsberg's (1981) interpretation of the annual mean monthly temperatures, as he suggested that the differences appear to be 'leveling off' by the 1960s. In fact, there now appears to be some indication of an actual reduced difference in minimum temperatures during the last 2 decades. This reduced difference appears to be explained by Woodstock's slightly rising minimum temperatures, not by some drop in the Baltimore temperatures. The urban-rural temperature differentials appear to follow the population trends of the Baltimore area (Fig. 5). There was a slight rise in the 1920s, followed by a leveling off until the 1960s. Although the minimum temperature differential peaks in the 1970s while Baltimore's population is decreasing, the surrounding counties of the metropolitan area reached a similar peak in the 1970s before starting a decline.

Fig. 4 also illustrates Woodstock's maximum and minimum temperatures subtracted from the first-order NWS stations Baltimore Washington International AP, Washington Dulles AP, and Washington National AP for the short time comparisons that can be made (postWWII). The largest differentials are seen for Washington National AP site in comparison to the other airports. This could be due to the more urban locale of the Washington National AP site in relation to the other airports. The Baltimore Washington International AP 

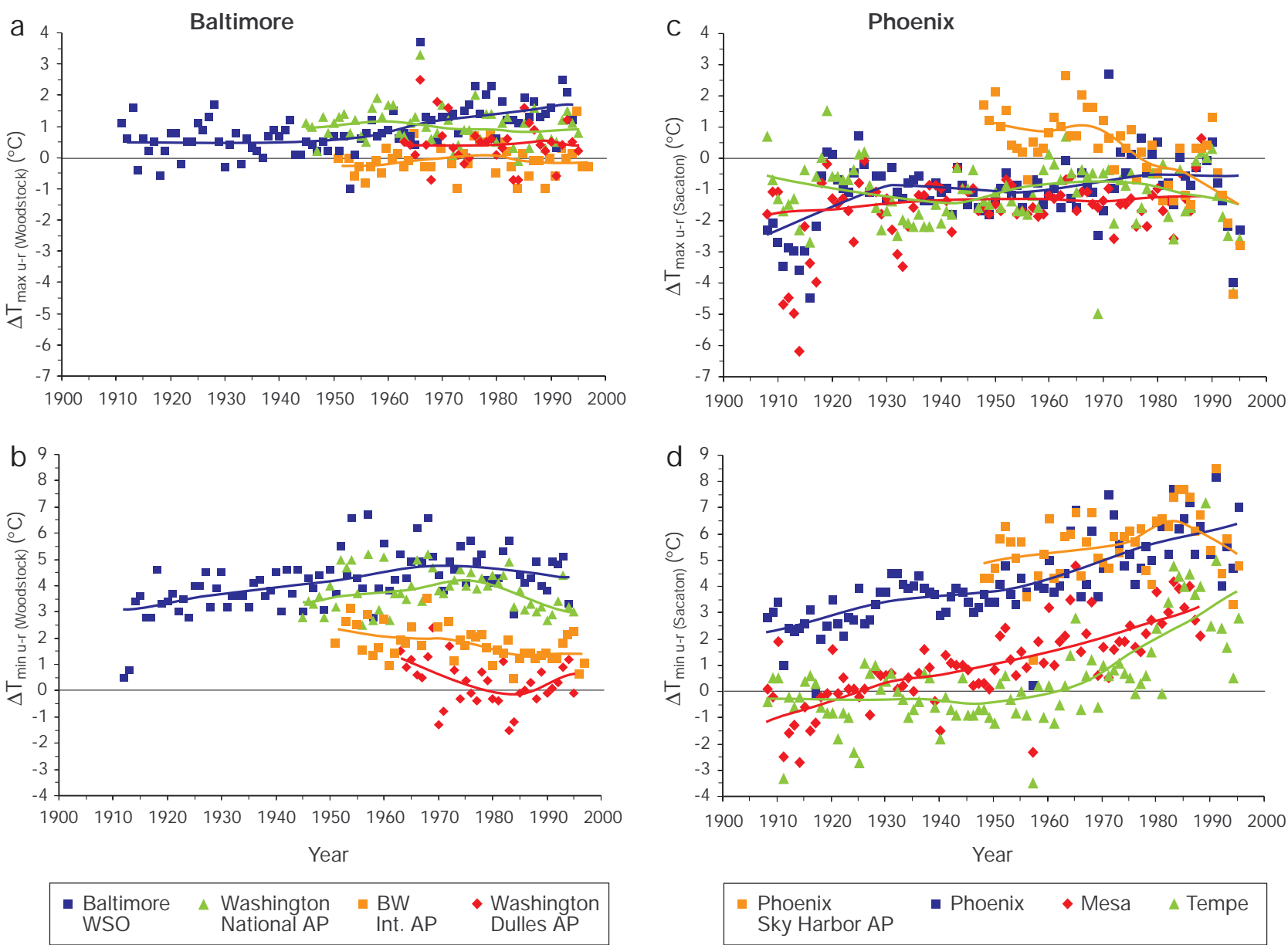

Fig. 4. Urban-rural monthly average maximum and minimum temperature differences. For the Baltimore sites: Baltimore WSO, Baltimore-Washington International AP, Washington Dulles AP and Washington National AP minus Woodstock for J uly. For the Phoenix sites: Phoenix Sky Harbor AP, downtown Phoenix, M esa, and Tempe minus Sacaton for May. (a,c) maximum temperature $\left(\Delta \operatorname{Tmax}_{\mathrm{u}-\mathrm{r}}\right)$ and $(\mathrm{b}, \mathrm{d})$ minimum temperature $\left(\Delta \mathrm{T} \min _{\mathrm{u}-\mathrm{r}}\right)$. Smooth lines fit to the time series were derived by the LOWESS smoothing procedure in SYSTAT (Wilkinson 1997) using a tension of 0.5

site just to the south of Baltimore also displays high minimum temperatures in comparison to Woodstock; the Washington Dulles AP site, on the other hand, has a much more rural behavior. The land use maps for 1900 to 1992 (Fig. 1) show the urban encroachment patterns toward these airport sites and the ranking of their temperature differences relative to Woodstock is consistent with the urbanization wave toward and around these sites. The decrease in $\Delta \operatorname{Tmin}_{\mathrm{u}-\mathrm{r}}$ through the 1970s and into the 1990s corresponds to the expansion of the Washington and Baltimore metropolitan areas toward Baltimore Washington International AP, Washington Dulles AP and Woodstock sites, respectively.

Trends in May $\Delta \operatorname{Tmax}_{\mathrm{u}-\mathrm{r}}$ and $\Delta \mathrm{T} \min _{\mathrm{u}-\mathrm{r}}$ for the Phoenix Sky Harbor AP, downtown Phoenix, Mesa, and Tempe (each site minus Sacaton's maximum/minimum data) illustrate the rapid rate of the urban effect with postWWII urban sprawl in this desert environment (Fig. 2). Although several previous analyses of Phoenix have shown a heat island effect (e.g., Balling \& Brazel 1987), data have not explicitly been compared with a desert site to illustrate the urban effect with the surrounding natural desert as a long-term time trend. Nor has previous research related the urban minus rural temperatures explicitly to decadal population data. Unlike the humid, forested environment around Baltimore, the rural desert surrounding Phoenix is normally the hottest area during the daytime (oasis effect). The higher daytime temperatures in rural Sacaton than at any of the urban sites make the maximum temperature differential negative relative to most of the Phoenix sites. The effect of irrigated agricultural land is clearly indicated by the large negative differentials for both 


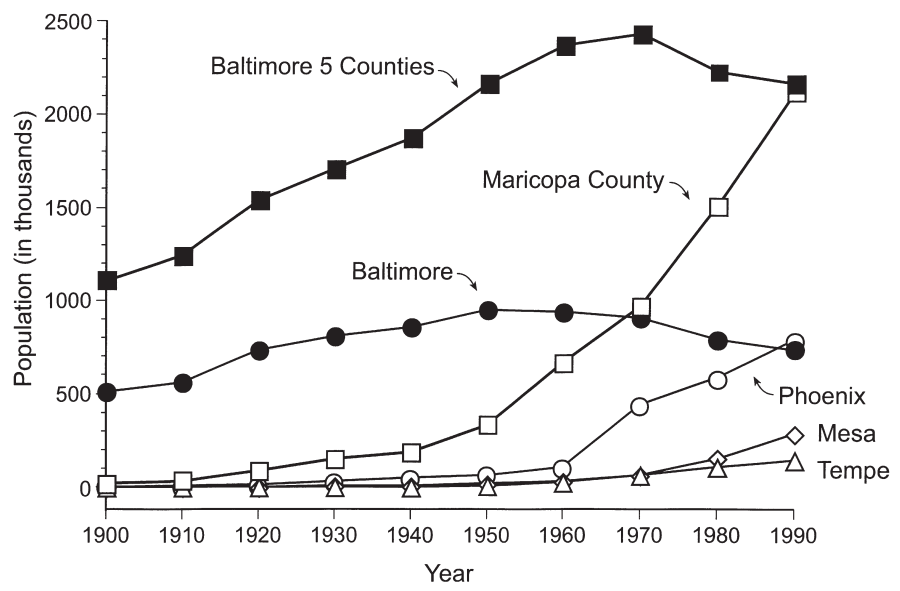

Fig. 5. Decadal population growth for the urban cities and counties (Maricopa in Arizona, and the 5 counties of Anne Arundel, Baltimore, Carroll, Harford, and Howard in the Baltimore region)

maximum and minimum temperatures at Mesa and Tempe through the 1960s. Tempe has remained cooler through most of the record, as it has largely been a residential community for metropolitan Phoenix and for Arizona State University, with an abundance of mature trees and a thickly vegetated landscape.

Until 1994, the airport temperature sensor at Phoenix Sky Harbor A P was located in a small asphalt parking lot between several buildings, surrounded by asphalt runways, next to the bare desert landscape of a dry riverbed. In 1994, this site was moved to an area over barren dirt and gravel just to the northeast of the airport's extensive asphalt runway system. It was also made an Automated Surface Observing System (ASOS) site at that time. This appears to be part of the reason for the abrupt downward $\Delta \mathrm{Tmin}_{\mathrm{u}-\mathrm{r}}$ differences in the 1990s (Fig. 4). Thus, even though this site is the only first-order site in the Phoenix area, its short record, station location changes, and instrument effects present challenges for use in this kind of temporal analysis. The effect of this station shift has been closely studied by the Office of the State Climatologist of Arizona, NOAA (National Oceanic and Atmospheric Administration), and a local power and water company known as the Salt River Project (SRP). SRP has analyzed the energy demand/temperature relationships for the city and metro area (Brazel et al. 1993). The airport's trends of downward maximum temperatures yet increasing minimum temperatures up to 1990 are, however, also consistent with urbanization effects noted in US rural versus urban temperature records (Karl et al. 1988). Minimums increase due to nighttime accentuation of the heat island, especially in climates with clear, calm nighttime conditions, such as often occur in Phoenix. Increased daytime convection due to excess heating of the urban environment could actually reduce the maximum temperatures through time. This may be the case for the Phoenix Sky Harbor AP record.

In the Phoenix area, population growth has been rapid post-WWII, and in the short time of some $50 \mathrm{yr}$, population in the metro area has approached that of the Washington and Baltimore region (which took some $200 \mathrm{yr}$ to grow to its current level). Thus, in onequarter of the time the Phoenix region has grown to a somewhat similar population (Fig. 5). As is the case in Baltimore, Phoenix's growth is being dwarfed by that of the county as a whole. This metropolitan expansion appears to be swallowing the formerly 'suburban' communities of Tempe and Mesa (Fig. 2), causing their $\Delta \operatorname{Tmin}_{\mathrm{u}-\mathrm{r}}$ trends to increase as the agricultural fringe moves farther away.

The above analyses show mean monthly effects for urban versus rural temperatures for months in summer with relatively little frontal activity. Extensive analysis for all monthly and annual periods is the subject of further analyses. Also, the above analysis is not meant to be representative of what Oke (1973) labels the ' $\Delta \mathrm{T}_{\mathrm{u}-\mathrm{r}(\max )}$ ', as this is a statistic that would represent the maximum diurnal urban-rural temperature difference with 'ideal' calm, clear skies and could be substantially larger than values indicated in this analysis. Given the procedures, rural sites chosen, and comparisons of May and J uly between Baltimore and Phoenix, the array of $\Delta \mathrm{Tmin}_{\mathrm{u}-\mathrm{r}}$ values are surprisingly consistent with the population differences. The $1.5^{\circ} \mathrm{C}$ difference in maximum heat islands between the cities of Baltimore and Phoenix (Baltimore being cooler) may be explained by J uly versus $M$ ay weather in the 2 cities and other factors that relate to the landscape and morphology of the 2 LTER regions. A full synoptic approach to this problem appears warranted and should be a subject for further investigation.

\section{CORRELATIONS WITH POPULATION DATA}

As suggested by previous researchers (e.g., Mitchell 1953, Oke 1973, Landsberg 1981, Karl et al. 1988), population acts as a surrogate for controlling factors on $\Delta \operatorname{Tmax}_{\mathrm{u}-\mathrm{r}}$ and $\Delta \mathrm{Tmin}_{\mathrm{u}-\mathrm{r}}$ time series between urban and rural temperatures. Oke (1973) pointed out that the logarithm of population is highly correlated with the maximum development of the heat island in various cities, and that this is logical based on the sky-view factor arguments he illustrated particularly for North American and European cities. Landsberg (1981) reviewed Oke's analysis and applied it to Columbia, Maryland, suggesting Oke's model fits exactly the short time series of maximum heat island development for that planned community. Karl et al. (1988) used a 
slightly different indicator by raising population numbers to the 0.45 power in their exhaustive treatment of many US rural and urban sites.

For this paper, we relate the $\Delta \operatorname{Tmin}_{\mathrm{u}-\mathrm{r}}$ and $\Delta \operatorname{Tmax}_{\mathrm{u}-\mathrm{r}}$ time series to decadal population statistics of Baltimore, Phoenix Sky Harbor Airport, Phoenix City, Tempe, and $M$ esa. We calculated decadal temperature differences by first smoothing the data by the LOWESS smoothing procedure in SYSTAT (Wilkinson 1997) using a tension of 0.5 , then using the decadal temperatures to match the census decadal-interval population data. Fig. 6 shows the $\Delta \operatorname{Tmin}_{\mathrm{u}-\mathrm{r}}$ and $\Delta \mathrm{Tmax}_{\mathrm{u}-\mathrm{r}}$ versus population relation. We leave the $x$-axis in a linear format, rather than log-transforming the population values, since the figure illustrates the non-linearity of the temperature response. Because Baltimore's population declined, we
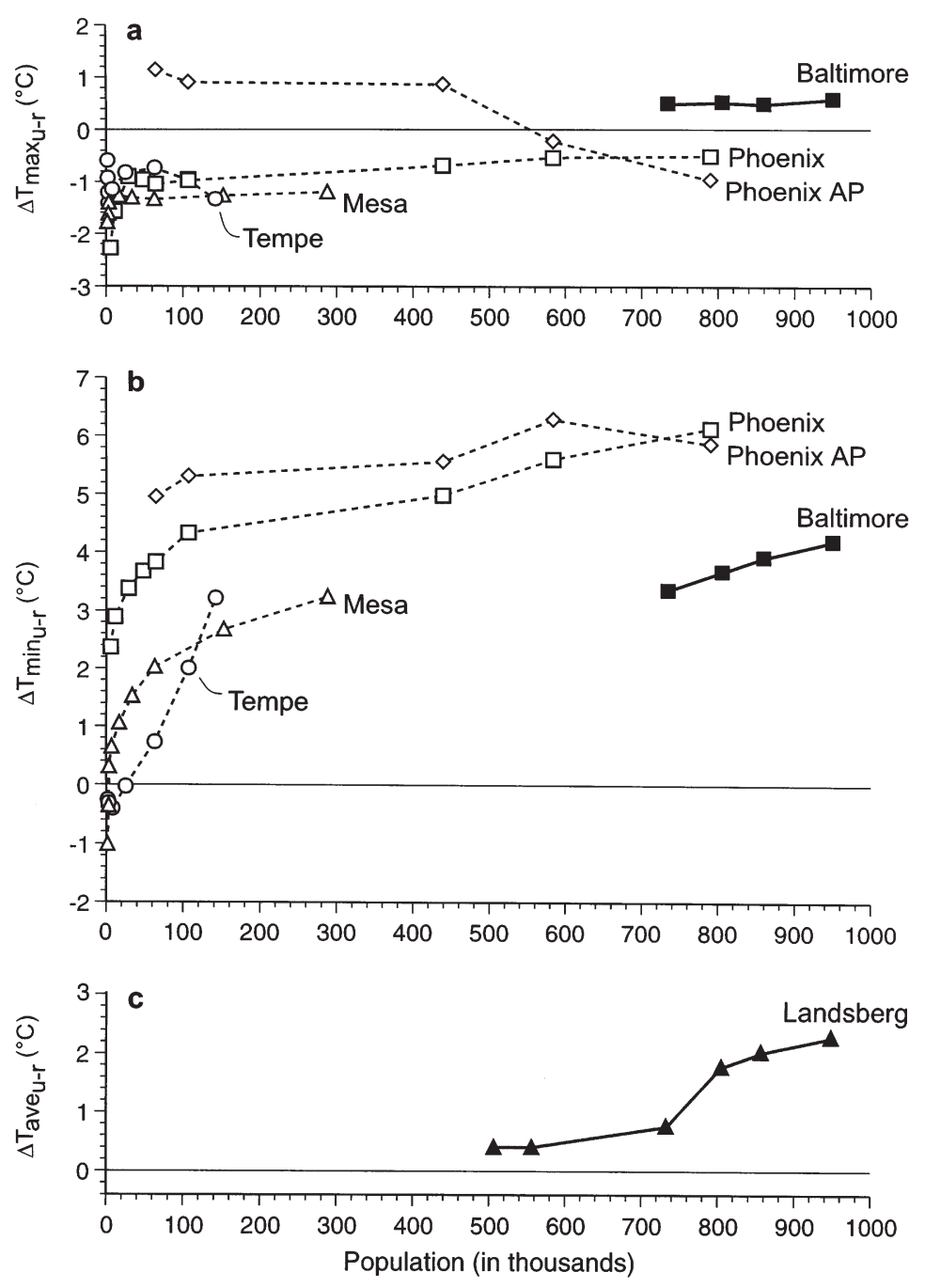

Fig. 6. Decadal (a) $\Delta \operatorname{Tmin}_{\mathrm{u}-\mathrm{r}}$ and (b) $\Delta \mathrm{T} \max _{\mathrm{u}-\mathrm{r}}$ data plotted as a function of population for the 5 cities, and (c) Landsberg's (1981) annual $\Delta$ Tave $_{u-r}\left({ }^{\circ} \mathrm{C}\right.$ ) Baltimore-Woodstock values for the period 1904 to 1979. Data in Phoenix for the month of May in Baltimore for the month of J uly plot only the period of its population growth in relation to temperature. It should be noted, however, that the temperatures did not continue to escalate after the period when the city population started on a downhill track.

As a city begins to develop, the minimum and maximum temperatures respond quickly to the new land surface conditions. The thermal regime appears to stabilize until a large population develops, wherein a new jump of particularly the minimum temperature occurs. The Oke (1973) explanation suggests that as the leading edge of a town or city encroaches on a climate site that site would experience a new regime associated with the town/city boundary layer of air. As time progresses and the city grows further around and past the site, there may be fewer options for major urban fabric changes, which therefore would be increasingly less significant as a feedback on the local climate. Also, with further urbanization, local feedbacks on the climate could result in the form of increased airflow (Balling \& Cerveny 1987) which would tend to slow down any further acceleration of the heat island. However, Karl et al. (1988) illustrated that as populations continue to increase toward the 1 million mark, the rate of the change of $\Delta \mathrm{Tmin}_{\mathrm{u}-\mathrm{r}}$ would accelerate, apparently to a new regime. They also suggested that abrupt shifts in the time series are characteristic of step-like development and architectural spurts common in large cities, although their data, which average together a large number of towns and cities, yielded vacillating characteristics of the time series of urban versus rural sites.

In computing the $\Delta \mathrm{Tmin}_{\mathrm{u}-\mathrm{r}}$ and $\Delta \mathrm{Tmax}_{\mathrm{u}-\mathrm{r}}$ as functions of population, we were restricted to decadal population census data. This large interval precludes identification of the potential lags that may exist as population and infrastructure change, and the climate responds by trying to attain a new equilibrium state. The lag may be as short as a few years, or as long as a decade or more. We were also unable to identify whether there are infrastructure or development thresholds below which climate is unchanged, and beyond some critical mass, the climate begins to respond. These are issues which need further study at smaller time and spatial scales.

We have plotted Karl et al.'s (1988) $\Delta \mathrm{Tmin}_{\mathrm{u}-\mathrm{r}}$ versus population curve, developed for annual data using their selection of 305 towns and cities, to illustrate the apparent 


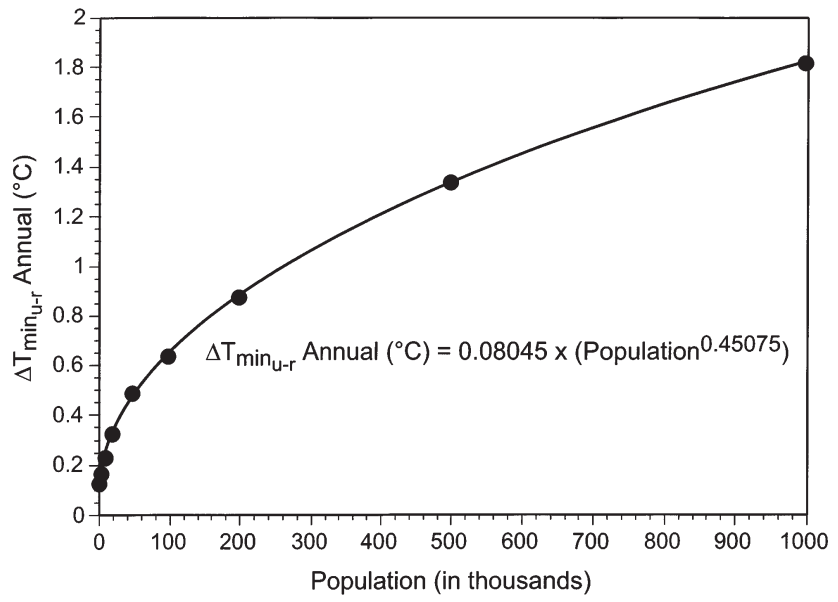

Fig. 7. Karl et al.'s (1988) $\Delta \operatorname{Tmin}_{\mathrm{u}-\mathrm{r}}$ versus population curve from annual data for 305 towns and cities

change as a city develops and builds into a large population (Fig. 7). The relation is also a non-linear function of population. Baltimore, M esa, Phoenix, and Tempe's plots of $\Delta \operatorname{Tmin}_{\mathrm{u}-\mathrm{r}}$ versus population patterns fit conceptually with Karl et al.'s (1988) analysis of the 305 US towns and cities (Fig. 7). Since in the Phoenix area climate records are available from virtually the beginning of the city development, the non-linear relation of $\Delta \operatorname{Tmin}_{\mathrm{u}-\mathrm{r}}$ to population is clear; but even in the case of Baltimore the leveling off phenomenon noted earlier by Landsberg (1981) appears to be consistent with this concept. Fig. 6 also shows Landsberg's annual $\Delta T_{a v e}$ to population curve for Baltimore-Woodstock for the period 1904 to 1979.

The absolute differences of $\Delta \operatorname{Tmin}_{\mathrm{u}-\mathrm{r}}$ between the 2 LTER regions likely relate to the months used, choice of rural sites used, adjacency to marine influences in Baltimore, and the calmer, less windy environment in Phoenix. A further, extensive year-round analysis of these 2 LTER regions is under investigation. Of considerable interest to ecologists as well, variations within the LTER regions relate to landscape and land use configurations, as indicated in Section 6. However, the rates of temperature change through time aggregated for both LTER sites in relation to characteristics of population and development reflect general concepts central to research on urban climatic processes, irrespective of the 2 diverse climate regimes in the LTER regions.

\section{SURFACE REMOTE SENSING AND PROCESS STUDIES}

The 2 cities have been studied by climatologists using remote sensing technology (e.g., Pease et al. 1976, Balling \& Brazel 1987, Lougeay et al. 1996). The focus has been the land cover mosaic and its relation to the complexities of the local pattern of urban climate. For the Baltimore area, a program entitled CARETS (Central Atlantic Regional Ecological Test Site) was initiated in the 1970s, when the city was at its highest level of its population. The purpose was to define the relations between land use and land cover and several important climatic factors through remote sensing, and to verify numerical simulations of surface climate (Reed \& Lewis 1978, Greene 1980, Nicholas \& Lewis 1980). These studies utilized remotely sensed data from low-level flights over Baltimore along set paths for sunrise, mid-morning, and the warmest period of summer days in 1972-73, employing the M-7 multispectral scanner of ERIM and Sky Lab's S-192 multispectral scanner. Landsat satellite data (120 m thermal band resolution) and ground sampling for mid-morning periods in summer 1992 in the Phoenix metropolitan area allowed for an assessment of the heat island (Lougeay et al. 1996).

A $n$ example of thermal images for the Baltimore and Phoenix metropolitan areas is shown in Figs. $8 \& 9$. The Baltimore image was taken on August 5, 1973, while the Phoenix image was taken on J une 24, 1992, both at ca 10:00 h Local Apparent Time. The image shown in Fig. 8 for Baltimore has a resolution of 720 m, as researchers developing this image 'block filtered' an original $72 \mathrm{~m}$ resolution image to provide more generalization to the patterns of temperatures. Thus, the Baltimore image appears blocky in comparison to the $120 \mathrm{~m}$ processed image for Phoenix. Details of processing and results are found in Pease et al. (1980) and Lougeay et al. (1996). Overall Phoenix is much warmer than Baltimore in these images, but the striking difference is the distinct urban signature in the Baltimore area, which is related to the population density (Fig. 10).

Several generalizations from these past remote-sensing studies can be made in relation to urban climate variations within cities. In these studies, land use classifications were developed and albedos, surface radiative temperatures, and corresponding meteorological data were collected. For this paper, we were interested in relative contrasts in surface thermal data (Table 2 ). Albedos of residential (not distinguished here between high and low density), commercial/industrial, and open areas are understandably higher across the Phoenix landscape, although tree canopy environments, croplands, and water surfaces in Phoenix have albedos similar to those in Baltimore. Comparisons of mid-morning radiant temperature differences between rural areas and city surfaces are difficult to make between the 2 cities. We have made a relative index by subtracting periphery land use values (forest in Baltimore; agriculture in Phoenix) from city surface values (Table 2). Water, cropland, forests, open field environments, and 


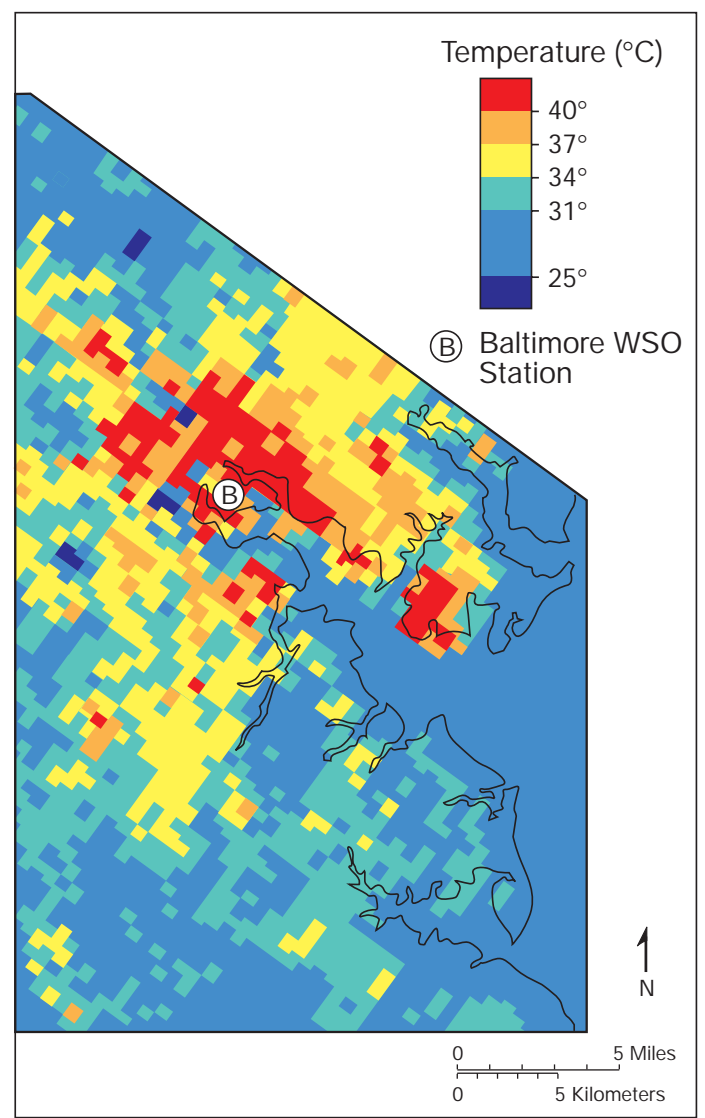

Fig. 8. Thermal image of the metropolitan area of Baltimore, August 5, 1973, ca 10:00 h LAT. Data from Pease et al. (1980); resolution $=720 \mathrm{~m}$
Table 2. Radiant temperatures $\left(\operatorname{Ts}\right.$ in ${ }^{\circ} \mathrm{C}$ ) and albedo $(\alpha)$ from past remote sensing studies in Baltimore (B) and Phoenix (P) for mid-morning summer conditions. Data were extracted from Pease et al. (1980) and Lougeay et al. (1996). Baltimore data: August 5, $1973,10: 00 \mathrm{~h}, \mathrm{Ta}$ (air temperature) $=24^{\circ} \mathrm{C}$, wind $=2.7 \mathrm{~m} \mathrm{~s}^{-1}, \mathrm{RH}$ (relative humidity) $=61 \%$. Phoenix data: J une $22,1992,10: 30 \mathrm{~h}, \mathrm{Ta}=35^{\circ} \mathrm{C}$, wind $=1.2 \mathrm{~m} \mathrm{~s}^{-1}, \mathrm{RH}=28 \%$. $\Delta \mathrm{T} s$ and $\Delta \alpha$ : for $\mathrm{B}$ are site data minus the forest/tree data; valuse for $\mathrm{P}$ are site data minus the cropland values

\begin{tabular}{|c|c|c|c|c|c|c|c|c|}
\hline \multirow[t]{2}{*}{ Land use } & \multicolumn{2}{|c|}{ Ts } & \multicolumn{2}{|c|}{$\alpha(\%)$} & \multicolumn{2}{|c|}{$\Delta \mathrm{Ts}$} & \multicolumn{2}{|c|}{$\Delta \alpha(\%)$} \\
\hline & B & $P$ & B & $\mathrm{P}$ & B & $\mathrm{P}$ & $B$ & $\mathrm{P}$ \\
\hline Residential & 27.9 & 38.1 & 16 & 19 & 2.4 & 6.1 & -6 & -3 \\
\hline $\begin{array}{c}\text { Commercial/ } \\
\text { industrial }\end{array}$ & 33.4 & 40.7 & 15 & 19 & 8.9 & 7.7 & -7 & -2 \\
\hline Crops & 24.2 & 32 & 20 & 21 & -0.3 & - & -2 & - \\
\hline Forest, trees & 24.5 & 32.8 & 22 & 19 & - & 0.8 & - & -2 \\
\hline Water & 24 & 33.6 & 12 & 12 & -0.5 & 1.6 & -10 & 9 \\
\hline Open & 25.4 & 41.2 & 22 & 25 & 1.4 & 9.2 & 0 & 4 \\
\hline Sand/desert & 34.9 & 43.1 & 10 & 25 & 10.4 & 11.1 & -12 & 4 \\
\hline Parks & 20.4 & 32 & 23 & 19 & -4.1 & 0 & 1 & -2 \\
\hline Range & 13.5 & 11.1 & 12 & 13 & & & & \\
\hline
\end{tabular}

residential areas are all considerably cooler, by 5 to $10^{\circ} \mathrm{C}$, in Baltimore than the densely built-up areas in the central business district and in commercial/ industrial locations. For Phoenix, the major contrast is between residential, commercial, open field, and desert surfaces versus well-watered agriculture, irrigated turf, tree-canopied environments and water surfaces, the difference being some 5 to $11^{\circ} \mathrm{C}$. Thus, the overall thermal contrasts between the immediate urban

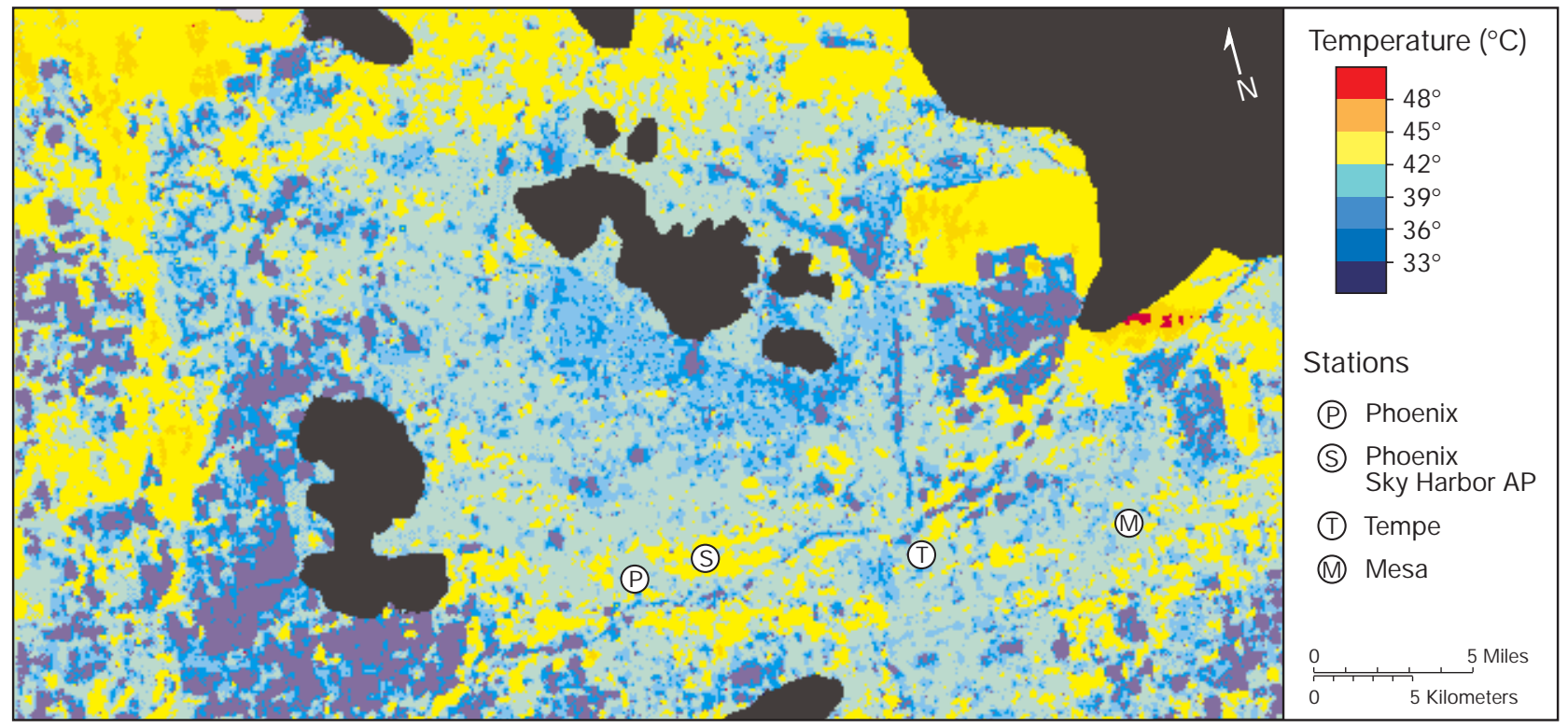

Fig. 9. Thermal image of the metropolitan area of Phoenix, J une 24, 1992, ca 10:00 h LAT. Data from Lougeay et al. (1996); resolution $=120 \mathrm{~m}$. Black areas are masked out due to clouds and/or steep terrain. Yellow (hotter) areas on the periphery are either barren agricultural lands or desert surfaces 

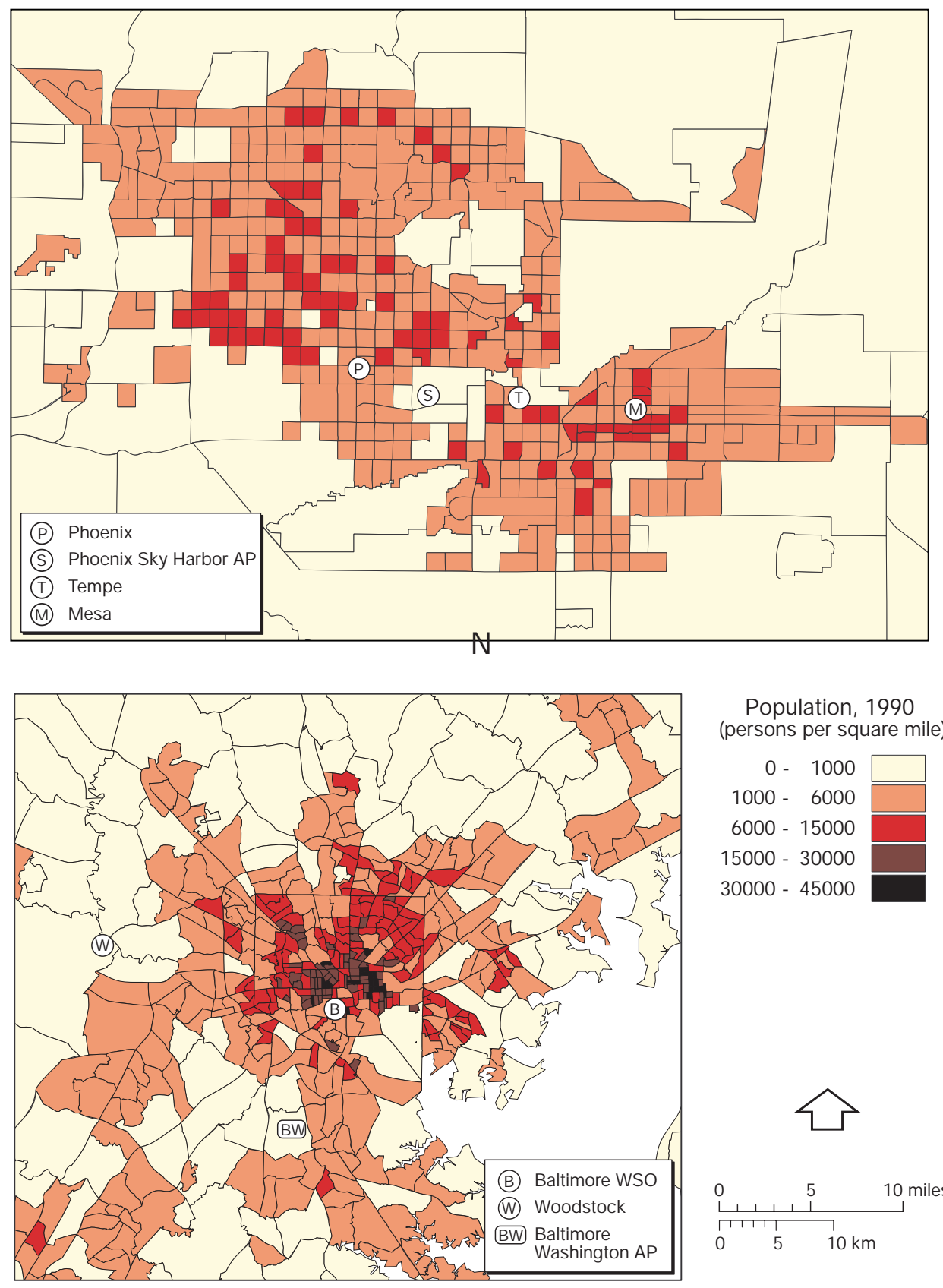

Population, 1990 (persons per square mile)

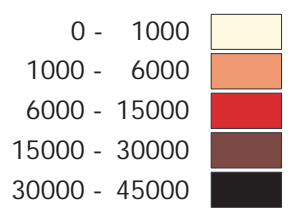

$30000-45000$

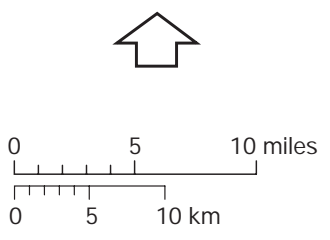

Fig. 10. 1990 population density maps of Baltimore and Phoenix, which are typically available in imperial units. For persons per square kilometer, the interval end points may be divided by ca 2.6 (e.g., 1000 per sq. mile to 385 per sq. km)

periphery and land uses in the city are surprisingly similar for the 2 cities. However, the geographic distribution, patterns, and density of various mosaics of land cover types across the urban and rural landscape (assumed correlated with population) are keys to the progression of $\Delta \operatorname{Tmin}_{\mathrm{u}-\mathrm{r}}$ patterns between the 2 cities. In the case of Baltimore, the urban fabric structure is considerably different than the urban sprawl environ- ment of Phoenix and its satellite towns and cities in the metropolitan area. Thus, a local-scale analysis is important in understanding the time series of temperature change for any given fixed point on the landscape and particularly the stations analyzed above. This work for the 2 cities is yet to fully unfold, but is a major objective (e.g., Heisler \& Wang 1998 for Atlanta) for both LTER study areas. 


\section{THE DEVELOPING FRINGE AND FUTURE WORK}

Landsberg's classic study, starting in the late 1960s, of developer J ames Rouse's Columbia, Maryland planned city illustrates the incipient evolution and test of the diversity of microclimates associated with typical new town/city development phases (Landsberg 1979). Similar research is underway for the urban periphery of the greater Phoenix area as part of an LTER project. Much can be learned from Landsberg's original study regarding why temperatures change in relation to population in a non-linear way as new towns emerge and grow into relatively large cities. This growth from small to larger populations can be analyzed on the urban fringe of metropolitan areas, as this is where land use and land cover changes are rapidly occurring. Such an empirical analysis is underway for the southeast metropolitan region of Phoenix by analyzing the decadal activity in the 'housing wave' spread across a previously agricultural landscape (Brazel et al. 1999).

For Baltimore, climate investigations are ongoing and related to microclimatic regimes over a wide range of local land use/cover, building on the work conducted in Atlanta using empirical methods relating land cover characteristics on scales of $10 \mathrm{~m}$ to $3 \mathrm{~km}$ to nearby meteorological sites (Heisler \& Wang 1998). This analysis, repeated over time, will be a good test of the functional factors that control local temperatures over space and time in urban LTER regions. For Phoenix, urban sprawl is a relatively new phenomenon in the 20th Century and retrospective analyses (e.g., noted in Pon et al. 1998), plus strategies similar to the Baltimore LTER program can also provide further insights into what happens to the surface climate across the metropolitan region at the incipient level of development and as towns/cities grow.

\section{CONCLUSIONS}

Long-term urban minus rural minimum temperature differentials have increased in both Baltimore and Phoenix as a function of population growth and the attendant infrastructure and land cover changes. $\Delta \operatorname{Tmin}_{\mathrm{u}-\mathrm{r}}$ increases for the 2 cities as a function of population growth; $\Delta \operatorname{Tmax}_{\mathrm{u}-\mathrm{r}}$ graphs do not show this due to mixing during the day, among other factors (e.g., humid, forested east coast region versus arid desert). Daytime temperatures are cooler in the Phoenix urban area than in the surrounding rural desert locales. A potential source of error in long-term temperature trend analyses is the mid-1990s changeover for US airport weather stations to automated ASOS instrumentation, often accompanied by location changes. The data are often discontinuous, and must be adjusted or corrected to account for the change.

This analysis also found that the apparent urbanrural differential may be decreasing in the last few years as the urban metropolis envelops previously rural sites. The designation of 'rural' should not specifically be identified for a site as a fixed definition through long periods of time, thus highlighting the fundamental disadvantage in urban-rural site selection and analyses, in general.

Both Phoenix and Baltimore appear to follow the $\Delta \operatorname{Tmin}_{\mathrm{u}-\mathrm{r}}$ versus population curve relationship noted by Karl et al. (1988), with an initial rapid increase, followed by a leveling off, and another increase as the population approaches 1 million. In Baltimore this relationship is not completely evident as the initial increase in population to $1 / 2$ million predates the temperature data.

The thermal imagery (Figs. $8 \& 9$ ) shows a very similar contrast between temperature and land covers for the 2 cities when the rural site is controlled or made similar as possible. Population densities (Fig. 10), however, are very different as Baltimore has a much more compact urban center while Phoenix is a sprawling western city. Population density may be a significant control on $\Delta \mathrm{Tmin}_{\mathrm{u}-\mathrm{r}}$ patterns as the thermal imagery reflects both the distinct dense urban core of Baltimore and the spread of Phoenix. As these 2 cities begin to redevelop their urban cores and further expand on the periphery, the effect of changes in the infrastructure and population density on $\Delta \mathrm{Tmin}_{\mathrm{u}-\mathrm{r}}$ and $\Delta \mathrm{T} \max _{\mathrm{u}-\mathrm{r}}$ time trends will be interesting to continue to monitor from fixed historical weather and climate stations. Since urban LTER work must focus on the urban ecosystem, it is important to link the climate system to social/land cover change indicators, so that the often-times difficult search for urban climate explanations can be unraveled.

Acknowledgements. This research is a contribution from the Central Arizona-Phoenix and the Baltimore Ecosystem Study (BES) LTER projects, supported by the National Science Foundation's Long-Term Studies Program (grant numbers DEB 9714833 and 97114835, respectively). Additional support for BES comes also from the EPA-NSF joint program in Water and Watersheds, project number GAD R825792. The USDA Forest Service Northeastern Research Station provides site management and in kind services to BES. NASA (NASA/NAGW-5040) contributes to BES data management and spatial analyses. We wish to thank Dr David Greenland, Chair of the National Climate Committee of LTER, for reviewing this paper. We would also like to acknowledge Patricia Gober of ASU Geography Department for assistance with the population census data; Co-PI Nancy Grimm of CAP LTER for encouragement on this effort; Sharolyn Anderson, ASU LTER geography assistant and Barbara Trapido-Lurie, academic professional in ASU Geography for cartography, and Sue Sisinni for assistance with graphic analysis. We would also like to thank 2 anonymous reviewers for their helpful comments. 


\section{LITERATURE CITED}

Balling RC J r, Brazel SW (1987) Time and space characteristics of the Phoenix urban heat island. J Ariz-Nev Acad Sci 21:75-81

Balling RC J r, Cerveny RS (1987) Long-term associations between wind speeds and the heat island of Phoenix, Arizona. J Clim Appl Meteorol 26:712-716

Brazel AJ, Verville HJ, Lougeay R (1993) Spatial-temporal controls on cooling degree hours: an energy demand parameter. Theor Appl Climatol 47:81-92

Brazel AJ, Selover N, Anderson S (1999) Microclimate and housing waves along the urban fringe. In: de Dear RJ , Potter JC (ed) Proceeding of the 15th International Congress of Biometeorology \& International Conference on Urban Climatology, 8-12 November 1999, Sydney, Paper ICUC 2.1

Court A (1974) The climate of the conterminous United States. In: Bryson RA, Hare FK (eds) Climates of N orth America, World Survey of Climatology, Vol 11. Elsevier Science Publishers, Amsterdam, p 193-261

Foresman TW, Pickett SRA, Zipperer WC (1997) M ethods for spatial and temporal land use and land cover assessment for urban ecosystems and application in the greater Baltimore-Chesapeake region. Urban Ecosys 1(4):201-216

Gallo KP, Owen TW (1998) Influence of land use/land cover on U.S. historical climate network temperature trends. In: Second Urban Environment Symposium, 13th Conference on Biometeorology and Aerobiology. American Meteorological Society, Boston, M A, p 65-68

Greene GM (1980) Testing an urban climate simulator. Geological Survey Professional Paper 1099-E, USGPO, Washington, DC

Greenland D, Swift LW J r (1991) Climate variability and ecosystem response: opportunities for the LTER network. Bull Ecol Soc Am 72:118-126

Heisler GM, Wang Y (1998) Semi-empirical modeling of spatial differences in below-canopy urban air temperature using GIS analysis of satellite images, on-site photography, and meteorological measurements. In: Second Urban Environment Symposium, 13th Conference on Biometeorology and Aerobiology. American Meteorological Society, Boston, M A, p 206-209

Karl TR, Diaz HF, Kukla G (1988) Urbanization: its detection

Editorial responsibility: Lawrence Kalkstein,

Newark, Delaware, USA and effect in the United States climate record. J Clim 1(11):1099-1123

Landsberg HE (1979) Atmospheric changes in a growing community (the Columbia, M aryland experience). Urban Ecol 4:53-81

Landsberg HE (1981) The urban climate. Academic Press, New York

Lougeay R, Brazel AJ, Hubble M (1996) Monitoring intraurban temperature patterns and associated land cover in Phoenix, Arizona using Landsat thermal data. Geocarta Int 114(4):79-90

Mitchell J M J r (1953) On the causes of instrumentally observed secular temperature trends. J M eteorol 10:224-227

M itchell J M J r (1961) The temperature of cities. Weatherwise 14:224-229

Nicholas FW, Lewis J E J r (1980) Relationships between aerodynamic roughness and land use and land cover in Baltimore, Maryland. Geological Survey Professional Paper 1099-C, USGPO, Washington, DC

Oke TR (1973) City size and the urban heat island. Atmos Environ 7:769-779

Pease RW, Lewis J E, Outcalt SI (1976) Urban terrain climatology and remote sensing. Ann Assoc Am Geogr 66(4): 557-569

Pease RW, J enner CB, Lewis J E J r (1980) The influences of land use and land cover on climate: an analysis of the Washington-Baltimore area that couples remote sensing with numerical simulation. Geological Survey Professional Paper 1099-A, USGPO, Washington, DC

Peterson TC, Vose RS (1997) An overview of the Global Historical Climatology Network database. Bull Am Meteorol Soc 78:2837-2849

Peterson TC, Vose RS, Razuvaev VN, Schmoyer RL (1998) GHCN quality control of monthly climate data. Int J Climatol 18:1169-1179

Pon B, Stamper-Kurn DM, Smith CK, Akbari H (1998) Existing climate data sources and their use in heat island research. Environmental Energy Technologies Division, Ernest Orlando Lawrence Berkeley National Laboratory, Berkeley

Reed WE, Lewis J E J r (1978) Land use and land cover information and air-quality planning. Geological Survey Professional Paper 1099-B. USGPO, Washington, DC Wilkinson L (1997) SYSTAT 7.0 Statistics. SPSS Inc, Chicago, IL

Submitted: J une 29, 1999; Accepted: J anuary 7, 2000

Proofs received from author(s): J une 21, 2000 